Portland State University

PDXScholar

$9-1-2008$

\title{
A Method for Processing Acoustic Doppler Current Profiler Velocity Data from Towed, Undulating Vehicles
}

David A. Jay

Portland State University

Jiayi Pan

Portland State University

Follow this and additional works at: https://pdxscholar.library.pdx.edu/cengin_fac

Part of the Civil and Environmental Engineering Commons

Let us know how access to this document benefits you.

\section{Citation Details}

Jiayi, P., \& Jay, D. A. (2008). A Method for Processing Acoustic Doppler Current Profiler Velocity Data from Towed, Undulating Vehicles. Journal Of Atmospheric \& Oceanic Technology, 25(9), 1710-1716.

This Article is brought to you for free and open access. It has been accepted for inclusion in Civil and Environmental Engineering Faculty Publications and Presentations by an authorized administrator of PDXScholar. Please contact us if we can make this document more accessible: pdxscholar@pdx.edu. 


\title{
A Method for Processing Acoustic Doppler Current Profiler Velocity Data from Towed, Undulating Vehicles
}

\author{
JiAYi PAN AND DAVID A. JAY \\ Department of Civil and Environmental Engineering, Portland State University, Portland, Oregon
}

(Manuscript received 6 October 2006, in final form 10 December 2007)

\begin{abstract}
The utility of the acoustic Doppler current profiler (ADCP) for sampling small time and space scales of coastal environments can be enhanced by mounting a high-frequency $(1200 \mathrm{kHz})$ ADCP on an oscillating towed body. This approach requires both an external reference to convert the measured shears to velocities in the earth coordinates and a method to determine the towed body velocities. During the River Influence on the Shelf Ecosystems (RISE) project cruise, a high-frequency $(1200 \mathrm{kHz})$ and narrowbeam ADCP with mode 12 sampling was mounted on a TRIAXUS oscillating towfish, which steers a 3D path behind the ship. This deployment approach extended the vertical range of the ADCP and allowed it to sample near-surface waters outside the ship's wake. The measurements from a ship-mounted 1200-kHz narrowbeam ADCP are used as references for TRIAXUS ADCP data, and a method of overlapping bins is employed to recover the entire vertical range of the TRIAXUS ADCP. The TRIAXUS vehicle horizontal velocities are obtained by removing the derived ocean current velocity from the TRIAXUS ADCP measurements. The results show that the method is practical.
\end{abstract}

\section{Introduction}

Studies of coastal environments often require highresolution velocity measurements throughout the water column over a broad area. The need for high resolution in space and time suggests use of a high-frequency acoustic Doppler current profiler (ADCP) that can detect finescale variations in currents (Hickey et al. 1998; Moum et al. 2003). However, such instruments have a limited vertical range and can sample only a small part of a typical $\sim 100-\mathrm{m}$ coastal water column from a fixed depth. The need for broad horizontal coverage and the inherent contradiction between range and resolution suggest deployment of a $1200-\mathrm{kHz}$ ADCP on a towed, undulating vehicle. Use of the enhanced sampling rate via RD Instruments' (RDI's) mode 12 feature is useful to improve accuracy. Mode 12 uses smaller depth cells, making it possible to measure highly sheared profiles of fast flows. In mode 1, small depth cells can result in

Corresponding author address: Dr. Jiayi Pan, Department of Civil and Environmental Engineering, Portland State University, P.O. Box 751, Portland, OR 97201.

E-mail: panj@cecs.pdx.edu noisy data unless long time averages are performed. Mode 12 gets around this by increasing the ping rate, allowing the depth cell size to be small without increasing the averaging time and data noise. In mode 12, each ping consists of a sequence of subpings, which are summed to ping averages.

The River Influence on the Shelf Ecosystems (RISE) project focuses on sampling the highly mobile Columbia River plume environment. The small time and space scales of the plume require rapid, high-resolution (in time and space) sampling. To meet these sampling criteria, we mounted an RDI $1200-\mathrm{kHz}$ ADCP on a TRIAXUS towfish, developed by MacArtney Underwater Technology Group Company, which was steerable such that it surfaced well outside the visible ship wake (MacArtney Underwater Technology Group 2005). The TRIAXUS towfish is steerable in 3D and, in a configuration installed on the R/V Point Sur, can reach depths of $\sim 200 \mathrm{~m}$. The ADCP on the TRIAXUS measures ocean current velocities relative to the TRIAXUS vehicle. To obtain the current velocities in the earth coordinates, we have to determine the TRIAXUS movements relative to the ship or the earth coordinates. The primary difficulty in carrying out this 

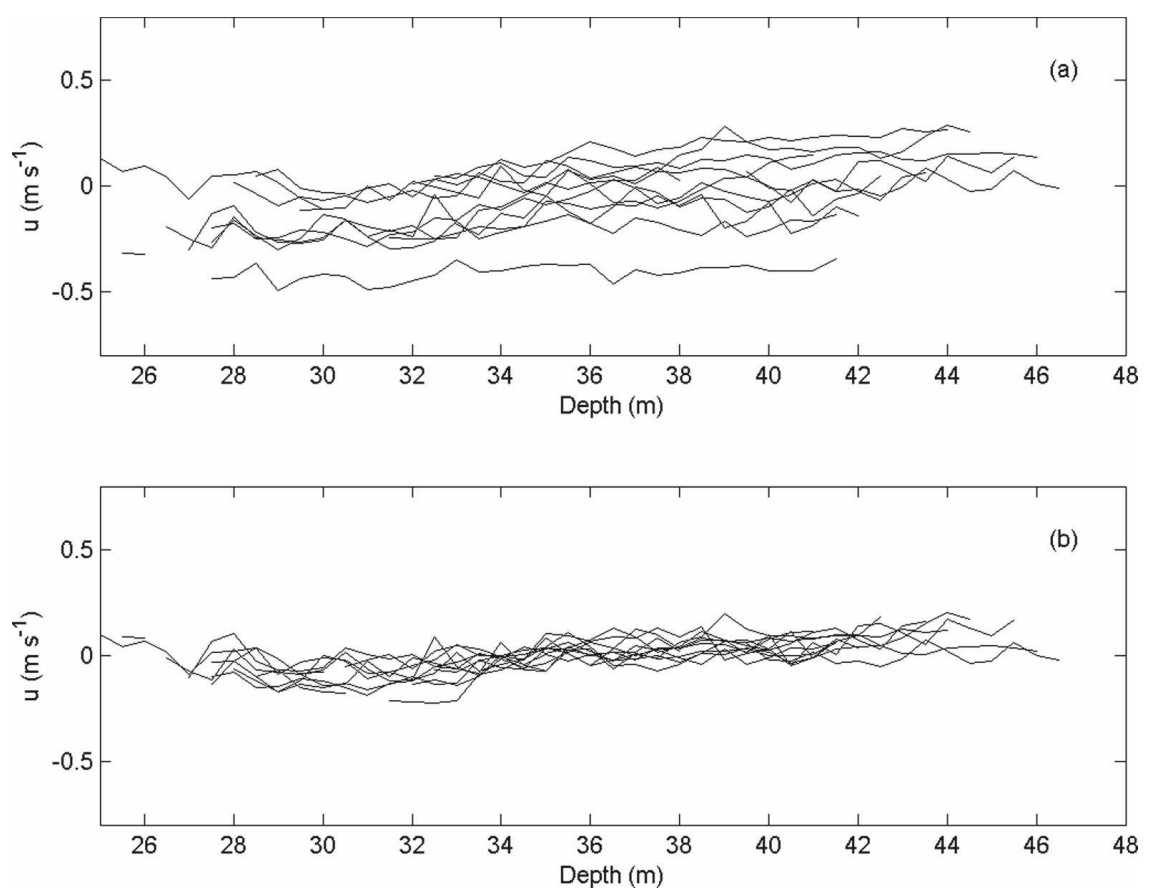

FIG. 1. (a) Neighboring east velocity $(u)$ profiles measured by the TRIAXUS ADCP, and (b) the velocity profiles removing their depth means, which illustrate the similarity among the profiles and the time-variable depth coverage achieved by the TRIAXUS ADCP.

procedure is to precisely determine the TRIAXUS vehicle movements. Visbeck (2002) used a linear inverse method to obtain depth profiles of the velocities from lowered ADCP (LADCP) sampling data. In this note, we introduce a simple method to process the TRIAXUS ADCP measured velocity data and recover the ocean current velocities in the earth coordinates.

\section{Methodology}

The 1200-kHz ADCP on the TRIAXUS was working in mode 12 with 10 subpings per ping and 1 ping per ensemble. The bin size is $0.5 \mathrm{~m}$ and the bin number is 46. The ADCP was mounted looking upward on the upper pontoon of the TRIAXUS twofish. Figure 1 shows 11 neighboring ensembles of the velocity profiles measured by the TRIAXUS ADCP. Although the ship navigation was removed from the ADCP-measured velocities, the measurements are still contaminated by TRIAXUS vehicle movements relative to the vessel. From Fig. 1a, one can see that there are offsets caused by TRIAXUS motions among these velocity profiles. Figure $1 \mathrm{~b}$ shows the velocity profiles removing their means and indicates that these velocity profiles keep the same shape, implying that the velocity shears are unaffected by the TRIAXUS vehicle motions. To give a metric for the consistency of the velocity profile shape, we calculate two root-mean-squares (rms): one is the rms between all the different velocity profiles,

$$
\mathrm{rms}_{1}=\sqrt{\frac{2}{S 2(S 2-1) S 1} \sum_{A=1}^{S 2-1} \sum_{B=A+1}^{S 2} \sum_{p=1}^{S 1}\left(\hat{u}_{p}^{A}-\hat{u}_{p}^{B}\right)^{2}}
$$

where $\hat{u}$ is the velocity removing its mean; $S 1$ is the number of velocity profile cells; $S 2$ is the number of velocity profiles; subscript $p$ represents the $p$ th velocity profile cell; and superscripts $A$ and $B$ denote different velocity profiles. The other is the rms of the detrended velocities,

$$
\mathrm{rms}_{2}=\sqrt{\frac{1}{S 1 S 2} \sum_{A=1}^{S 2} \sum_{p=1}^{S 1} \hat{u}_{p}^{\prime A},}
$$

where $\hat{u}^{\prime}$ is the detrended velocity. The $\mathrm{rms}_{1}$ represents the difference between velocity profiles and $\mathrm{rms}_{2}$ shows the data uncertainty within velocity profiles. For the case of Fig. $1, \mathrm{rms}_{1}=0.08 \mathrm{~m} \mathrm{~s}^{-1}$, and $\mathrm{rms}_{1}=0.05 \mathrm{~m} \mathrm{~s}^{-1}$. Here, we have $\mathrm{rms}_{1}<2 \mathrm{rms}_{2}$.

To correct the TRIAXUS ADCP-measured velocities, we had another $1200-\mathrm{kHz}$ ADCP mounted on a pole fixedly attached to the ship. The ship-mounted ADCP had the same configurations as that on the TRIAXUS, and measured a velocity layer from 3.0- to $20-\mathrm{m}$ 


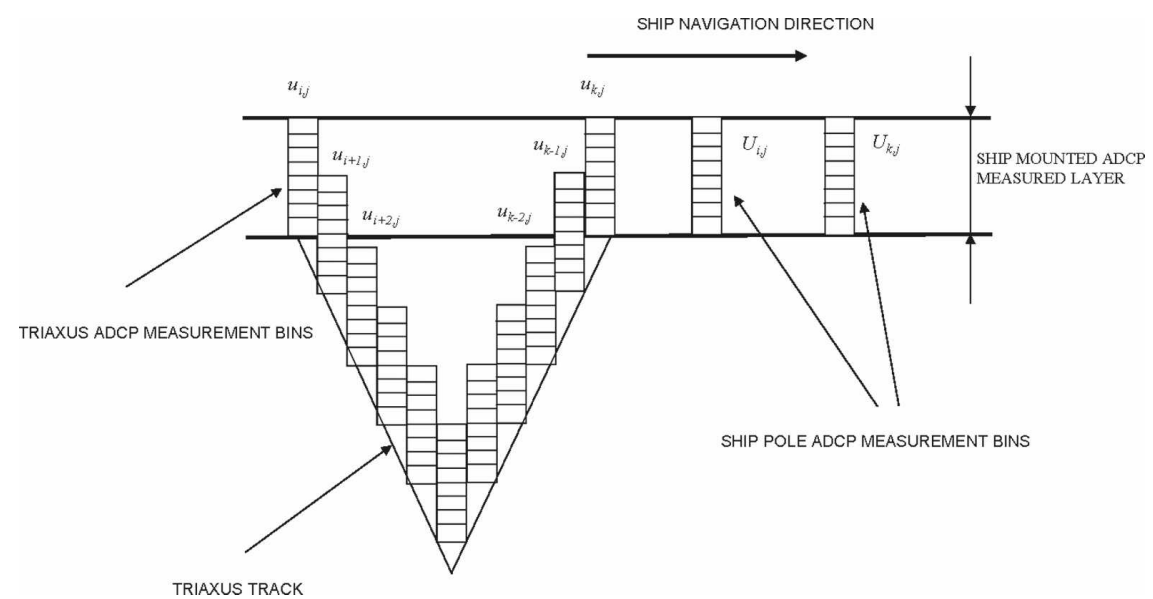

FIG. 2. Schematic diagram of the TRIAXUS and ship-mounted ADCP measurements. In fact, the ship-mounted and TRIAXUS ADCPs had forty-six 0.5-m bins.

depth. The vessel velocities were determined using a shipboard GPS, and therefore, we can obtain absolute current velocities in the earth coordinates, which are employed as references for the TRIAXUS ADCPmeasured velocities. However, the TRIAXUS vehicle sometimes cycled to a depth beyond the range of shipmounted ADCP measurements, so that the TRIAXUS and ship-mounted pole ADCPs did not overlap. In this situation, the following method is used to solve the problem. Figure 2 is a schematic map of the two ADCP measurements. In the figure, $u_{i, j}$ and $u_{k, j}$ represent the velocities measured by the TRIAXUS ADCP. The subscripts $i$ and $k$ denote the $i$ th and $k$ th ensemble, and the subscript $j$ represents the $j$ th bin, so $j$ is a function of depth; $U_{i, j}$ and $U_{k, j}$ are the ship-mounted ADCP measurements and have already been corrected to be in the earth coordinates by using the ship's GPS navigation data. There are offsets between $u_{i, j}$ and $U_{i, j}$ and between $u_{k, j}$ and $U_{k, j}$, resulting from TRIAXUS vehicle motions relative to the vessel. For the method, there are two steps as below.

1) For the ensembles with overlapping bins between the two ADCPs (ensembles $i, i+1, k-1, k$ in Fig. 2 ), the TRIAXUS vehicle velocities $\left(u_{i}^{t}\right.$ and $\left.u_{k}^{t}\right)$ relative to the vessel (at ensembles $i$ and $k$, respectively) satisfy

$$
\begin{gathered}
\left.u_{i, j}\right|_{j=1,2,3, \ldots, M}+u_{i}^{t}=\left.U_{i, j}\right|_{j=1,2,3, \ldots, M} \\
\left.u_{k, j}\right|_{j=1,2,3, \ldots, M}+u_{k}^{t}=\left.U_{k, j}\right|_{j=1,2,3, \ldots, M},
\end{gathered}
$$

where $N$ is the bin number (46), $M$ is the overlapping bin number, and the superscript $t$ represents TRIAXUS parameters. Using Eq. (3), we can determine TRIAXUS vehicle velocities $u_{i}^{t}$ and $u_{k}^{t}$, as well as $u_{i+1}^{t}$ and $u_{k-1}^{t}$ in the ensembles with overlapping bins between TRIAXUS and ship-mounted ADCPs.

2) For the ensembles without overlapping bins between the two ADCPs (ensembles $i+2, i+3, \ldots$, $k-3, k-2$ in Fig. 2), we determine the TRIAXUS vehicle velocities by comparing the neighboring ensembles. In Fig. 2, one can see that $u_{i+2, j}$ and $u_{i+1, j}$ have vertical overlapping bins. We assume the two neighboring ensembles of velocity measurements have a negligible difference, which gives

$$
\left.u_{i+1, j}^{c}\right|_{j=L_{1}, \ldots, M}=\left.u_{i+2, j}\right|_{j=1, \ldots, M-L_{1}+1}+u_{i+2}^{t},
$$

where $L_{1}$ represents the first bin of ensemble $i+1$ overlapping with $i+2 ; u_{i+1}^{c}$ denotes the corrected TRIAXUS ADCP-measured current velocity. Using Eq. (4), we get TRIAXUS vehicle velocity $u_{i+2}^{t}$, and in same manner, we solve the TRIAXUS velocities at ensembles $i+3, i+4, \ldots, k-3$, and $k-$ 2 step by step. However, this procedure may magnify errors from $i+3$ to $k-2$, since we do not consider the difference between two neighbor ensembles. The errors could be accumulated from $i+$ 3 to $k-2$, so the accuracies of $u_{c}$ and $u_{t}$ decrease step by step. For ensemble $k-1$, if we neglect the difference between $k-2$ and $k-1$, we have

$$
\left.u_{k-1, j}^{c}\right|_{j=L_{2}, \ldots, M}=\left.u_{k-2, j}\right|_{j=1, \ldots, M-L_{2}+1}+u_{k-2}^{t},
$$

where $L_{2}$ represents the first bin of ensemble $k-1$ overlapping with $k-2$. Using Eq. (5), we can obtain the TRIAXUS velocity at time $k-2\left(u_{k-2}^{t}\right)$. Fur- 

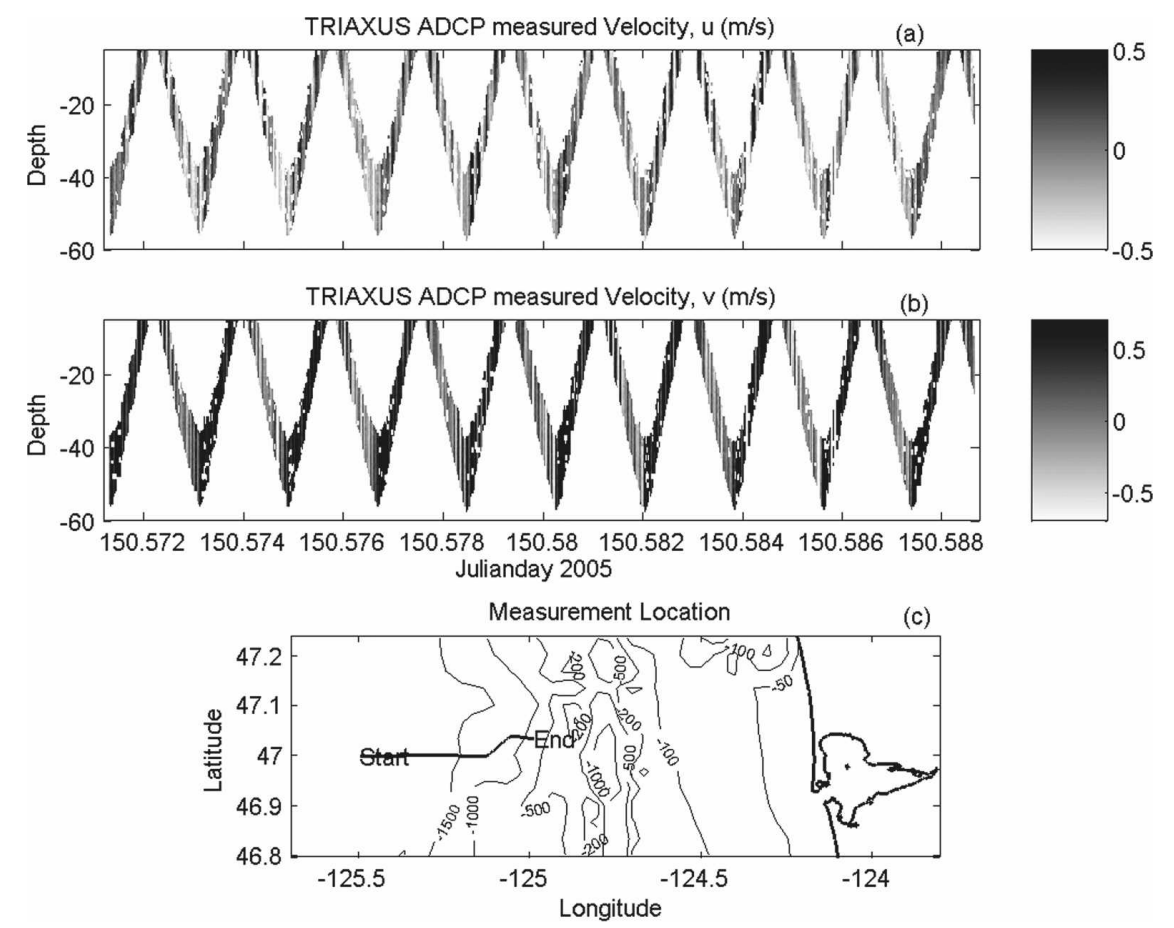

FIG. 3. Uncorrected TRIAXUS ADCP-measured velocities, (a) $u$ component and (b) $v$ component, in a (c) segment of a cruise transect between $46.9990^{\circ} \mathrm{N}, 125.3376^{\circ} \mathrm{W}$ and $47.0000^{\circ} \mathrm{N}, 125.2711^{\circ} \mathrm{W}$.

thermore, $u_{k-3}^{t}, u_{k-4}^{t}, \ldots$, and $u_{i+2}^{t}$ are solved. The derivation procedure is from $k-2$ to $i+2$, and therefore, the accuracies decrease from $k-2$ to $i+$ 2, which are opposite to those of first group of the solution. Let the first solution group be referred to as $u_{m, j}^{t, i}$, and the second as $u_{m, j}^{t, k}$, where $m$ represents ensembles $i+2, i+3, \ldots, k-3, k-2$. To make optimal estimations of the TRIAXUS velocities between $i+2$ and $k-2$, we use a weighted average to combine two groups of solutions, namely

$$
\overline{u_{m, j}^{t}}=\alpha_{1} u_{m, j}^{t, i}+\alpha_{2} u_{m, j}^{t, k},
$$

where $\alpha_{1}$ and $\alpha_{2}$ are weighted coefficients related to the distances between $i$ and $m$ and between $m$ and $k$, respectively. The corrected TRIAXUS ADCPmeasured velocity can be derived by

$$
u_{i, j}^{c}=u_{i, j}+\overline{u_{m, j}^{t}} \text {. }
$$

\section{Results}

Figures $3 \mathrm{a}$ and $3 \mathrm{~b}$ show a segment of TRIAXUS ADCP-measured $u$ and $v$ velocities, respectively, from which the ship navigation velocities were removed. The segment is between $46.9990^{\circ} \mathrm{N}, 125.3376^{\circ} \mathrm{W}$ and $47.0000^{\circ} \mathrm{N}, 125.2711^{\circ} \mathrm{W}$, and is a part of the measure- ment transect in Fig. 3c. Figures $3 a$ and $3 b$ exhibit great undulations in the raw velocities, revealing that the TRIAXUS motion relative to the vessel contaminates the velocity observations.

We corrected the TRIAXUS ADCP-measured velocities using the method introduced here. The results are shown in Fig. 4. Figures $4 a$ and $4 b$ give the shipmounted ADCP-measured velocity $u$ component and the corrected TRIAXUS ADCP-measured $u$, respectively. Figures $4 \mathrm{c}$ and $4 \mathrm{~d}$ specify the $v$ components of the ship-mounted ADCP and corrected TRIAXUSmeasured velocities, respectively. In the ship transect between $47^{\circ} \mathrm{N}, 125.2741^{\circ} \mathrm{W}$ and $46.9986^{\circ} \mathrm{N}, 125.2030^{\circ} \mathrm{W}$ (Figs. 4a and 4c on Julian day of 2005 between 150.5879 and 150.6079), one can see that a northeastward current occupied the surface layer with a depth of $5 \mathrm{~m}$. Between 5 and $8 \mathrm{~m}$, this current turned eastward. This feature is also shown in the TRIAXUS-measured velocities in Figs. 4b and 4d. In Fig. 4a, there was a westward current appearing in the ship transect between $46.9970^{\circ} \mathrm{N}$, $125.1436^{\circ} \mathrm{W}$ and $47.0186^{\circ} \mathrm{N}, 125.0885^{\circ} \mathrm{W}$ (Fig. 4a on Julian day of 2005 between 150.6216 and 150.6391) below $5 \mathrm{~m}$, which was also captured by the TRIAXUS ADCP (Fig. 4b). At the 10-m depth in the same position, Fig. 4c shows a southward current that also appeared in Fig. 4d. In addition, Figs. 4b and 4d indicate 


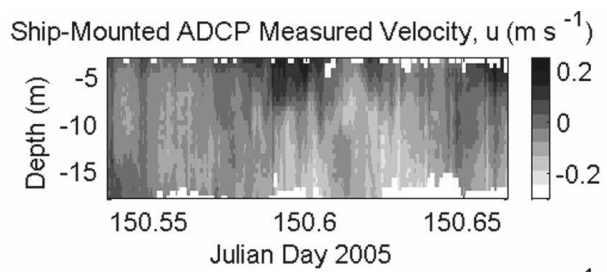

Corrected TRIAXUS ADCP Measured Vel., $\mathrm{u}\left(\mathrm{m} \mathrm{s}^{-1}\right)$
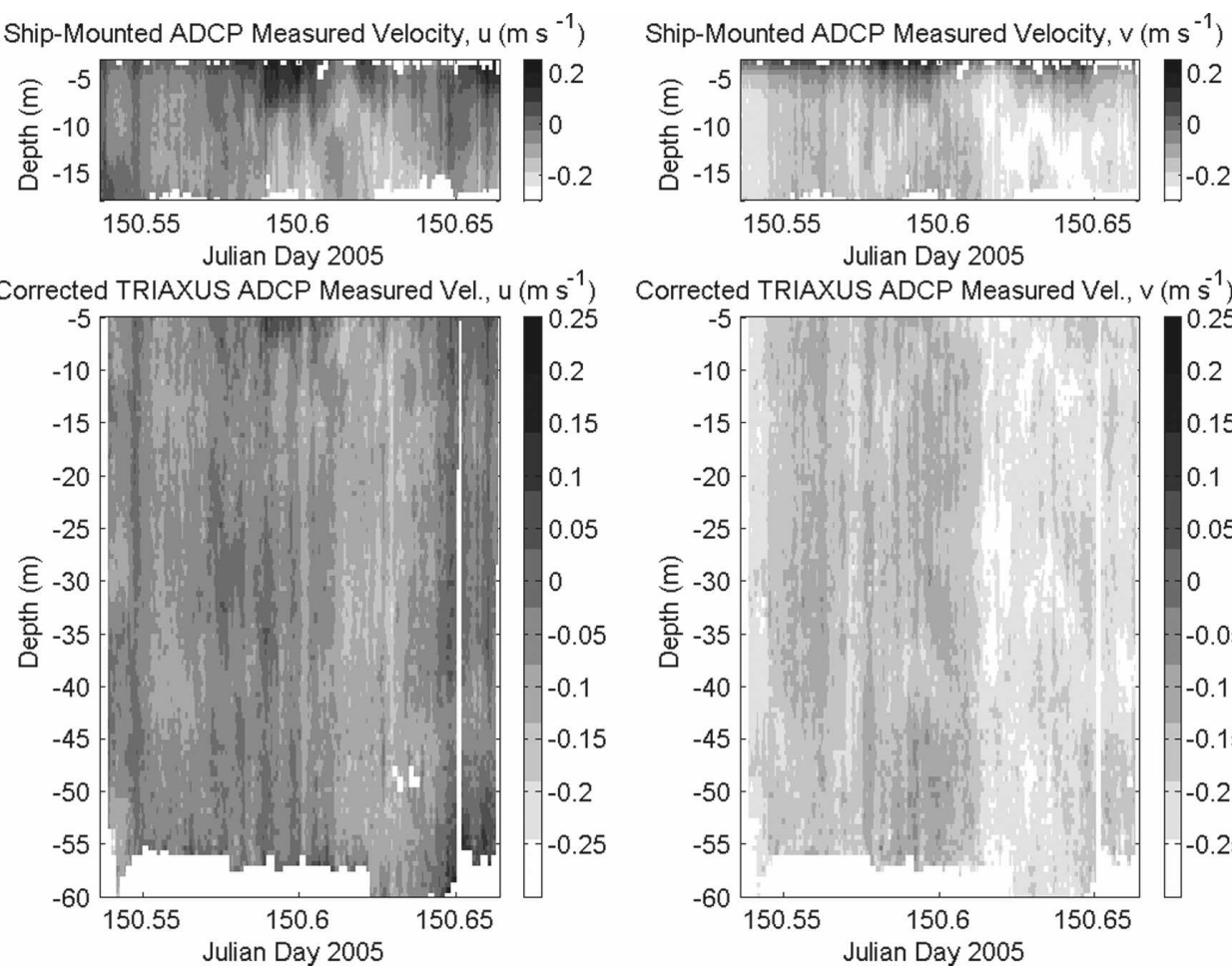

Corrected TRIAXUS ADCP Measured Vel., $v\left(\mathrm{~m} \mathrm{~s}^{-1}\right)$

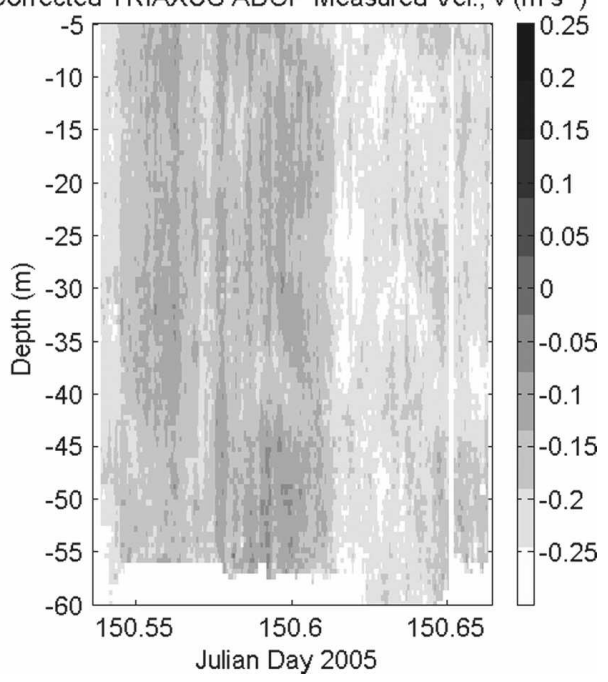

FIG. 4. The ship-mounted ADCP-measured velocities, (a) $u$ and (c) $v$ components, and the corrected TRIAXUS ADCP-measured velocities, (b) $u$ and (d) $v$ components.

that there was a southwestward current occupying a depth between 30 and $40 \mathrm{~m}$ in this subtransect. In Fig. $4 \mathrm{~b}$, one can see a positive velocity region, which reveals that an eastward current existed in the ship transect between $47.0351^{\circ} \mathrm{N}, 125.0610^{\circ} \mathrm{W}$ and $47.0349^{\circ} \mathrm{N}$, $125.0166^{\circ} \mathrm{W}$ (on Julian day of 2005 between 150.6489 and 150.6607), and strengthened at a depth of 50-60 m. These results show that the TRIAXUS ADCP measurements can detect deeper current structures than the ship-mounted ADCP.

Comparisons between the corrected TRIAXUS ADCP-measured velocities and the ship-mounted ADCP measurements are given in Fig. 5. Figures 5a and $5 \mathrm{~b}$ show the $u$ and $v$ components of the shipmounted and TRIAXUS ADCP-measured velocities at the 8-m depth, respectively. The rms of the velocity difference between the two ADCP measurements is $0.024 \mathrm{~m} \mathrm{~s}^{-1}$ for $u$ and $0.025 \mathrm{~m} \mathrm{~s}^{-1}$ for $v$. Figures $5 \mathrm{c}$ and $5 \mathrm{~d}, 5 \mathrm{e}$ and $5 \mathrm{f}$, and $5 \mathrm{~g}$ and $5 \mathrm{~h}$ show the time series of the velocity $u$ and $v$ components at depths of 12,14 , and 16 $\mathrm{m}$, respectively, whereas at these depths, the rms difference between two ADCP measurements for $u$ and $v$ is calculated as 0.026 and $0.023 \mathrm{~m} \mathrm{~s}^{-1}, 0.042$ and 0.025 $\mathrm{m} \mathrm{s}^{-1}$, and 0.042 and $0.023 \mathrm{~m} \mathrm{~s}^{-1}$, respectively.

The TRIAXUS vehicle velocities relative to the vessel are derived and shown in Fig. 6. Figure 6a illustrates the $u$ component and Fig. $6 \mathrm{c}$ displays the $v$ component.
One can see that the velocities oscillate between -0.8 and $0.8 \mathrm{~m} \mathrm{~s}^{-1}$ in a certain frequency. This oscillation is consistent with the TRIAXUS depth undulation cycle. We calculate the power spectra of the TRIAXUS motion velocities, which are shown in Figs. $6 \mathrm{~b}$ ( $u$ component) and $6 \mathrm{~d}(v$ component). There are three spectrum peaks in the figures; the largest is at the frequency $0.0068 \mathrm{~Hz}$ (period: $2.45 \mathrm{~min}$ ), the second is at $0.0132 \mathrm{~Hz}$ (period: $1.26 \mathrm{~min}$ ), and the third is at $0.0196 \mathrm{~Hz}$ (period: $51 \mathrm{~s})$. Obviously, the period $51 \mathrm{~s}$ corresponds to the TRIAXUS vehicle depth oscillation cycle. The second and third could be the harmonics of the low-frequency peak because the TRIAXUS is not perfectly sinusoidal.

\section{Discussion and summary}

In Visbeck's method (VM), a least squares equation was developed by using all the ADCP bins including the overlapping ones. To solve the barotropic velocity profile from the least squares equation, he used three constraints: zero current assumption, bottom tracking, and ship navigation. These constraints could construct an invertible model matrix $(\mathbf{G})$ and make the least squares equation solvable. To recover all depths of the ADCP velocity, we also use overlapping bins as a connection between neighboring ensembles. However, the three constraints proposed by Visbeck (2002) are not available for our cases. Thus, we use the ship-mounted 

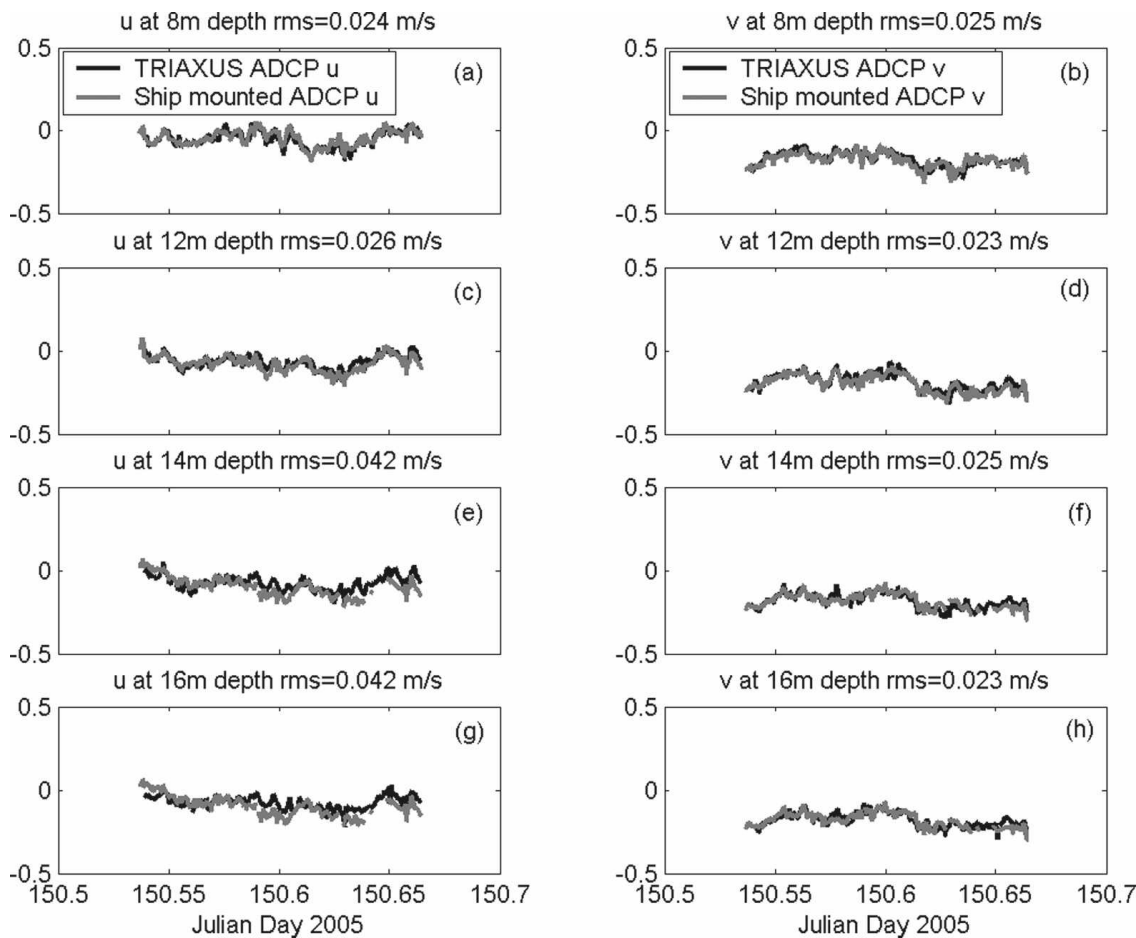

FIG. 5. Comparisons between the ship-mounted ADCP-measured velocities and the corrected TRIAXUS ADCP-measured velocities at depths of (a),(b) 8, (c),(d) 12, (e),(f) 14, and (g),(h) $16 \mathrm{~m}$. The (left) $u$ component and (right) $v$ component.
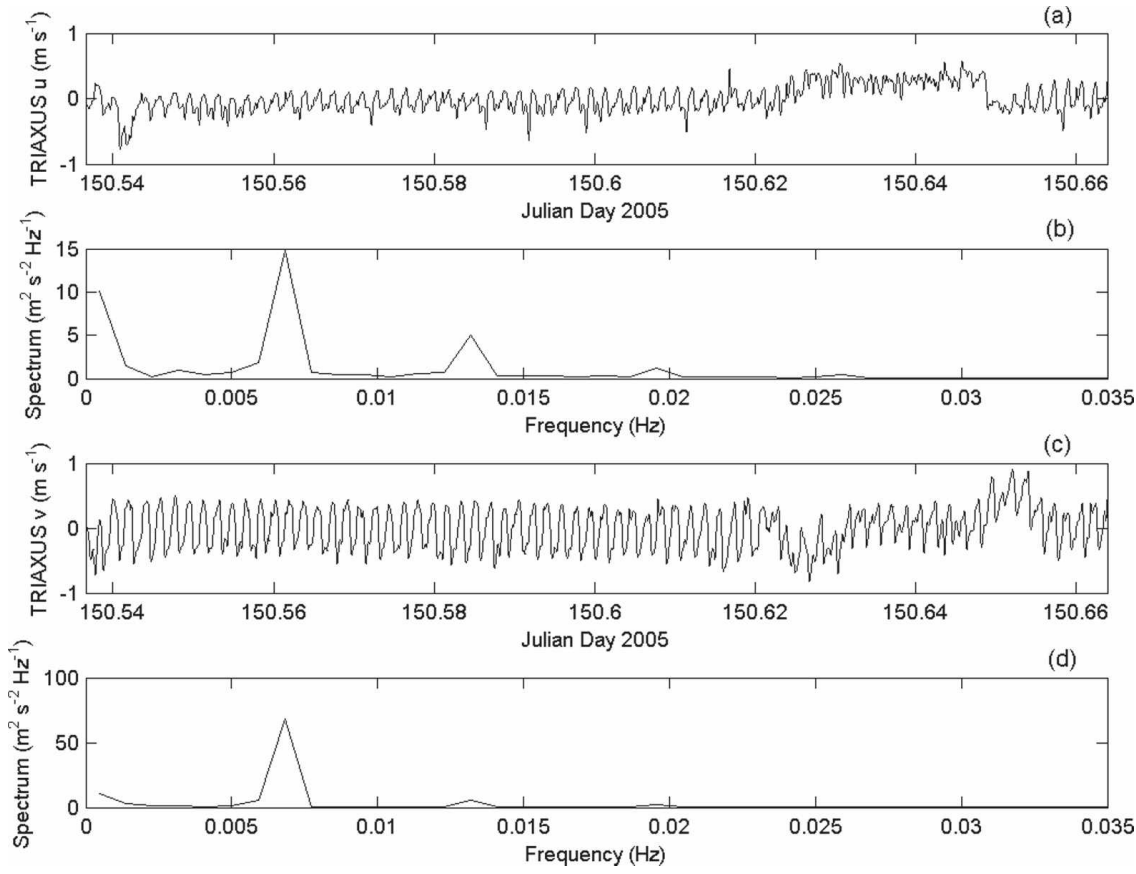

FIG. 6. The (a) $u$ and (b) $v$ components of the TRIAXUS vehicle velocities and the power spectra of the velocity (c) $u$ and (d) $v$ components. 
ADCP velocity measurements for constraints rather than the zero current assumption, bottom tracking, and ship navigation. This is like building a new model matrix for the VM. The method in this note does not need the matrix inversion, but uses simple, step-by-step calculations to obtain the velocity profile, and therefore takes less computer time. In addition, this method uses the ship ADCP measurements as the references, which allows the variations of ocean current velocities between ensembles. In general, this method provides an alternative way to recover the undulated ADCP velocity profiles.

The TRIAXUS towed vehicle can oscillate in a water depth and make the onboard high-frequency ADCP acquire a deeper velocity profile. In this note, we introduce a method to remove the TRIAXUS ADCP vehicle velocities from the measurements and obtain the TRIAXUS vehicle motions relative to the ship in the earth coordinates. The results show that the corrected TRIAXUS ADCP-measured velocities could capture not only surface layer current features as measured by a ship-mounted ADCP but also the features in a deep depth up to $60 \mathrm{~m}$. The comparison between the two ADCP measurements shows that rms differences between the velocities measured by ship-mounted and TRIAXUS ADCPs at depths of 8, 12, 14, and $16 \mathrm{~m}$ are less than $0.042 \mathrm{~m} \mathrm{~s}^{-1}$. An analysis of the derived TRIAXUS vehicle motion velocities reveals that the vehicle horizontal velocities relative to the vessel have an oscillation consistent with the vehicle depth undulation.

Acknowledgments. The study is supported by the National Science Foundation RISE (River Influences on Ecosystems) Project OCE 0239072. We thank Captain Ron L. Short of the R/V Point Sur and Marine Technicians Stewart Lamberdin and Ben Jokinen for their superb support of in situ data collection. The authors are also grateful to the anonymous reviewers for their valuable suggestions and comments.

\section{REFERENCES}

Hickey, B. M., L. J. Pietrafesa, D. A. Jay, and W. C. Boicourt, 1998: The Columbia River plume study, subtidal variability in the velocity and salinity fields. J. Geophys. Res., 103, 10339 10368.

MacArtney Underwater Technology Group, 2005: TRIAXUS towed undulator. Doc. 2005-001E. [Available online at http://www.triaxus.com/filer/1021/TRIAXUS-TowedUndulator.625266203754055.pdf.]

Moum, J. N., D. M. Farmer, W. D. Smyth, L. Armi, and S. Vagle, 2003: Structure and generation of turbulence at interfaces strained by internal solitary waves propagating shoreward over the continental shelf. J. Phys. Oceanogr., 33, 2093-2112.

Visbeck, M., 2002: Deep velocity profiling using lowered acoustic Doppler current profiles: Bottom tracking and inverse solution. J. Atmos. Oceanic Technol., 19, 794-807. 
Copyright of Journal of Atmospheric \& Oceanic Technology is the property of American Meteorological Society and its content may not be copied or emailed to multiple sites or posted to a listserv without the copyright holder's express written permission. However, users may print. download, or email articles for individual use. 